\title{
THE EDITORS' NOTE REGARDING THE NOTICE OF RETRACTION
}

Referring to the "Expression of Concern due to Plagiarism" inserted as the Message from the Editor-in-Chief in the International Journal of Occupational Medicine and Environmental Health (2006, 19(2):145-150), the Editors announce the retraction of the article "The role of selenium in cancer and viral infection prevention" by Anna Luty-Frąckiewicz published in our Journal (2005;18(4): 305-11).

The Editors have first discovered the plagiarism from the paper "The importance of selenium to human health" written by M. Rayman, which appeared in The Lancet (2000;15(9225):233-41).

Then, following the procedure developed by the International Committee of Medical Journal Editors, the Editors of the International Journal of Occupational Medicine and Environmental Health have applied to the Index Medicus for the withdrawal of the paper by Anna Luty-Frackiewicz from indexation and marking its abstract with the following note: "plagiarism - scientific misconduct".

At present under further investigations, another additional plagiarism was found, as the text very closely resembled a previously published articles: by Divadkar-Navsariwal et al. "The link between selenium and chemoprovention: A case for selenoproteins" (J Nutr 2004;194:2899-902) and by Beck et al. "Selenium deficiency and viral infection" (J Nutr 2003;133(5 Suppl 1):1463-67).

It is with great regret to say that whole passages of the above articles have been drawn by A. Luty-Frąckiewicz by using the "cut and paste" method.

We publish this editorial to inform the medical community on scientific misconduct and also to prevent similar attempts of plagiarism in the future.

Editorial Board 